\title{
Combination therapy in the treatment of hypertension
}

\author{
Carolina Guerrero-García MD ${ }^{1,2}$, Alberto Francisco Rubio-Guerra PhD ${ }^{1,2}$ \\ 'Unidad de Investigación Clínico-Metabólica, Hospital General de Ticomán SS DF, Mexico City, Mexico; \\ ${ }^{2}$ Mexican Group for Basic and Clinical Research in Internal Medicine, A.C., Mexico City, Mexico
}

\begin{abstract}
Hypertension is a major preventable risk factor for atherosclerosis and ischemic heart disease. Although modern and effective antihypertensive drugs are available, most patients remain with a suboptimal blood pressure control. Most hypertensive patients will need a combination of antihypertensive agents to achieve the therapeutic goals - recent guidelines recommend initiating treatment with two drugs in those patients with a systolic blood pressure $>20 \mathrm{mmHg}$ and/or a diastolic blood pressure $>10 \mathrm{mmHg}$ above the goals, and in those patients with high cardiovascular risk. In addition, approximately $25 \%$ of patients will require three
\end{abstract}

antihypertensive agents to achieve the therapeutic targets. In this review, we analyse the latest information available regarding the treatment of hypertension with combination therapy.

Keywords: antihypertensive drugs, cardiovascular disease, combination therapy, hypertension, therapeutic goals.

\section{Citation}

Guerrero-García C, Rubio-Guerra AF. Combination therapy in the treatment of hypertension. Drugs in Context 2018; 7: 212531. DOI: 10.7573/dic.212531

\section{Introduction}

Hypertension is a serious global health issue, affecting millions of patients. Despite having various antihypertensive agents that have shown their efficacy and safety, the percentage of patients achieving the recommended therapeutic goals is unacceptably low [1]. Hypertension is a risk factor for cardiovascular disease uncontrolled hypertension increases the relative risk from two to four times for coronary disease, stroke, heart failure, peripheral arterial disease, renal insufficiency, atrial fibrillation and dementia/cognitive impairment. Undoubtedly, poorly controlled hypertensive patients have an increased risk for cardiovascular complications [1].

Hypertension has a prevalence of $30.5 \%$ in Mexico, which is almost the same reported by other Latin-American countries, except for Colombia and Peru [2]. Its prevalence continues to increase with age. Consequently, in subjects over 70 years, the prevalence of hypertension reaches $60-70 \%$ [3]. Despite the effectiveness of modern antihypertensive drugs, approximately $70 \%$ of hypertensive patients fail to achieve the therapeutic goal of blood pressure $<140 / 90 \mathrm{mmHg}$ with monotherapy; and even less patients will reach the new therapeutic goals $<130 / 80$ mmHg recommended in the 2017 ACC/AHA/AAPA/ABC/ACPM/ AGS/APhA/ASH/ASPC/NMA/PCNA Guideline for the Prevention, Detection, Evaluation, and Management of High Blood Pressure in Adults [4], using only one antihypertensive drug. In fact, long-term prospective studies have shown that hypertensive patients were not effectively treated with monotherapy and needed an average of three drugs for adequate control $[1,5]$.

\section{Rationale for combination therapy}

When hypertensive patients do not achieve adequate control of their blood pressure, the options to try and achieve required treatment goals are to increase the dose of monotherapy (which increases the risk of side effects) or to use drug combinations with minimum side effects. In order to avoid complications, it is important to start treatment as soon as possible, achieve the goals in the shortest time possible and ensure treatment adherence $[1,6]$.

The mechanisms that lead to a blood pressure increase in a patient are diverse - monotherapy acts on one or at best two of these mechanisms, while the use of combinations of drugs allows for action on several different hypertensive mechanisms [7]. By combining two drugs with different mechanisms of action, an antihypertensive effect of two to five times greater than that obtained by monotherapy is possible $[7,8]$. Increasing the dose of monotherapy reduces coronary events by $29 \%$ and cerebrovascular events by $40 \%$, while combining two antihypertensive agents with a different mechanism of action 
reduces coronary events by $40 \%$ and cerebrovascular events by $54 \%$ [9]. Thus, the use of combination therapy provides greater protection to a target organ than increasing the dose of monotherapy.

In summary, combination therapy looks like a better option than increasing the dose - the advantages of combination therapy are shown in Box 1 [1].

Fixed-dose combinations (both drugs in the same tablet) offer additional advantages, such as improved adherence by $24 \%$, easier indications and potentially reduced cost. Their limitation is less possibility of titrating the dose of only one of the drugs $[7,10]$.

Both the eighth report of the Joint National Committee for the Prevention, Detection, Evaluation and Treatment of Hypertension (JNC8) [11] and the 2013 guidelines of the European Society of Hypertension and the European Society of Cardiology (ESHESC) for the management of hypertension [12] recommend the use of combinations of antihypertensive agents from the beginning for subjects in which the probability of achieving the recommended treatment goals in hypertension with monotherapy is low, as are patients with systolic pressure $20 \mathrm{mmHg}$ above the target or diastolic pressure $10 \mathrm{mmHg}$ above the target or more.

Reinforcing the above, a meta-analysis published in 2009 showed that patients receiving more antihypertensive drugs

\section{Box 1. Advantages of the combination of antihypertensive drugs.}

Greater reductions in blood pressure figures compared with monotherapy

Reduction in adverse effects:

- RASIs prevent pretibial edema induced by calcium channel blockers

- RASIs counteract the release of renin caused by natriuretics

- RASIs block the release of aldosterone induced by natriuretics and the resulting hypokalemia

Several physiopathological mechanisms of increased blood pressure are blocked

Greater protection to target organs

Faster control of blood pressure

Combinations may have some effects that are independent of their antihypertensive action:

- Anti-inflammatory

- Metabolic

Anticounter regulation:

- Diuretics counteract the retention of water produced by vasodilators

- RASIs compensate for renin release by diuretics

RASI, renin-angiotensin system inhibitor. achieved (as expected) lower blood pressure figures and had greater reductions in the appearance of cardiovascular and cerebrovascular events [13].

Several clinical studies have shown that hypertensive patients, with high cardiovascular risk, benefit more from receiving combinations of medications, as well as subjects with moderate hypertension and low cardiovascular risk [8].

\section{Looking at the evidence}

Clinicians have a wide range of antihypertensive drugs for the management of hypertensive patients, all safe and effective, and which have been shown to reduce mortality and complications in these patients $[11,12]$. However, there are few studies that show us the safety and efficacy of the different combinations in the management of arterial hypertension. The recommended and not recommended combinations are shown in Table 1.

Most combinations of antihypertensive agents, whether at fixed doses or free combinations, include a diuretic. These combinations have been shown to produce greater blood pressure reductions than those seen with monotherapies [8]. Combinations of a calcium antagonist with a renin-angiotensin system inhibitor (RASI), whether an angiotensin-converting enzyme inhibitor (ACEI) or angiotensin receptor blocker (ARB), have also been shown to be effective and safe in the management of the hypertensive patient $[7,9]$. The available evidence on these drug combinations is now presented.

The only study that directly compares two combinations of antihypertensive drugs is the Avoiding Cardiovascular Events Through Combination Therapy in Patients Living With Systolic Hypertension (ACCOMPLISH). In this study, 11,462 high-risk cardiovascular patients over 55 years of age $(60.4 \%$ with diabetes mellitus) were included. They were divided into two groups - one group received the combination benazepril plus amlodipine, and the other group received the combination benazepril plus hydrochlorothiazide. Trial duration was designed for 5 years; however, the study was suspended at month 39 because the calcium antagonist plus ACEI combination was found to be superior to the ACEI plus hydrochlorothiazide combination in reducing cardiovascular, cerebrovascular and renal events, despite a similar reduction in systolic and diastolic values in both groups (the mean difference in blood pressure between the two groups at the end of the study was $0.9 \mathrm{mmHg}$ systolic and $1.1 \mathrm{mmHg}$ diastolic) [14].

The renal outcomes of the Ongoing Telmisartan Alone or in combination with Ramipril Global Endpoint Trial (ONTARGET) study included 25,620 participants, who were randomly assigned to ramipril, telmisartan or to a combination of both drugs [15]. After 56 weeks follow-up, the combination of telmisartan plus ramipril significantly increased the risk of dialysis, doubling serum creatinine, and caused a greater fall in the glomerular filtration rate than the ramipril or telmisartan groups, which has called into question the benefits of this combination. 
Table 1. Antihypertensive combinations.

\section{Recommended combinations}

Diuretics with angiotensin-renin axis inhibitors or calcium antagonists

Inhibitors of the renin-angiotensin axis with diuretics or with calcium antagonists

Beta-adrenergic blockers with dihydropyridine calcium antagonists

\section{Not recommended combinations}

Two agents that inhibit the renin-angiotensin axis (derived from a warning published by the Food and Drug Administration, dated 20 April 2012, and [12])

Diuretics with beta blockers (greater risk of development of type 2 diabetes, as found in the ASCOT trial [19])

Beta-adrenergic blockers with non-dihydropyridine calcium antagonists (greater risk for bradycardia and/or atrio-ventricular block [12])
In the Aliskiren Trial in Type 2 Diabetes Using Cardio-Renal Endpoints (ALTITUDE), 8561 patients were randomly assigned to aliskiren or placebo as an adjunct to another RAS inhibitor; however, the trial was stopped prematurely after a median follow-up of 32.9 months [16]. In the Aliskiren Study in Post-MI patients to Reduce remodelling (ASPIRE) trial, the addition of aliskiren to the standard therapy, including an inhibitor of the RAAS in 820 high-risk post-MI patients, was associated with more adverse effects, and did not result in further attenuation of left ventricular remodeling after a follow-up of 26-36 weeks [16]. These two studies provided sufficient evidence that the combination of a direct inhibitor of renin (aliskiren) with ACEI or ARB should be avoided [16]. In 2012, the Food and Drug Administration advised that combinations of two agents that act on the renin-angiotensin axis should not be used, particularly if one of the agents is aliskiren. In summary, combinations of two agents that act on the renin-angiotensin axis should not be used $[9,16]$.

Although sacubitril plus valsartan (a neprilysin inhibitor plus an ARB combination) is approved for the treatment of heart failure, its antihypertensive efficacy has also been demonstrated, as per the Prospective Comparison of Angiotensin Receptor Neprilysin Inhibitor With Angiotensin Receptor Blocker Measuring Arterial Stiffness in the Elderly (PARAMETER) trial [17]. Sacubitril plus valsartan was superior to olmesartan in reducing both central aortic and brachial pressures in 454 elderly patients with systolic hypertension and arterial stiffness, after 52 weeks follow-up.

\section{Effects independent of antihypertensive action}

Combinations of antihypertensive drugs have actions unrelated to their effect on blood pressure that can have an impact on the prognosis of patients.

\section{Metabolic effects}

Antihypertensive drugs have distinct metabolic effects. Both beta blockers and diuretics are associated with insulin resistance and a higher risk of type 2 diabetes, whereas ACEls and ARBs improve insulin resistance [18].

Beta blockers and thiazides increase triglyceride levels, whereas calcium channel blockers increase high density lipoprotein levels [18].

In the Anglo-Scandinavian Cardiac Outcomes Trial-Blood Pressure Lowering Arm (ASCOT BPLA study), 19,257 patients with hypertension who had at least three other cardiovascular risk factors and aged 40-79 years were assigned to receive either amlodipine (adding perindopril as required) or atenolol (adding bendroflumethiazide and potassium as required). In this study, the amlodipine-based regimen was more effective in reducing cardiovascular events than the atenolol-based regimen [19]. At the end of the study, several metabolic variables differed significantly from baseline to final visit between treatment regimens; triglycerides and glucose had a significant reduction $(p<0.0001)$ in the amlodipine-based group, whereas high density lipoprotein levels significantly $(p<0.0001)$ increased in the amlodipine-based group [19].

In the Study of Trandolapril-Verapamil SR and Insulin Resistance (STAR) trial, there were 240 hypertensive patients with glucose intolerance who were followed for 1 year [20]. The combination of trandolapril plus verapamil was more effective than the combination of losartan plus hydrochlorothiazide in reducing the risk of new-onset diabetes mellitus. Our group reported that the same combination of trandolapril plus verapamil increased adiponectin levels [21] and reduced resistin levels [22] more than ACEI monotherapy - both desirable effects in hypertensive patients at high cardiovascular risk.

In the OLAS study (OLmesartan plus Amlodipine versus olmesartan plus hydrochlorothiazide in metabolic syndrome), there were 120 patients with metabolic syndrome and Stage I and Stage II hypertension who were randomised to receive either olmesartan plus amlodipine or olmesartan plus hydrochlorothiazide with follow-up ended at 78 weeks [23]. At the end of the study, it was found that, with the same level of blood pressure lowering, the olmesartan plus amlodipine combination had a greater beneficial effect on some metabolic 
parameters (measured as the insulin resistance index) than the olmesartan plus hydrochlorothiazide combination. In addition, insulin levels decreased, insulin resistance decreased, adiponectin levels increased, and there was a lower occurrence of new cases of diabetes mellitus, in patients given the calcium antagonist combination compared with the hydrochlorothiazide combination.

\section{Nephroprotective effect}

Two studies with combined therapy showed that the progression of normoalbuminuria to microalbuminuria in hypertensive type 2 diabetic subjects can be stopped. In the Bergamo Nephrologic Diabetes Complications Trial (BENEDICT), 1204 subjects were randomly assigned to receive treatment with trandolapril plus verapamil, trandolapril alone, verapamil alone, or placebo over 3 years [24]. At the end of the study, the use of trandolapril plus verapamil decreased the progression from normoalbuminuria to microalbuminuria. In the Action in Diabetes and Vascular Disease (ADVANCE) trial, there were 11,140 patients with type 2 diabetes who were randomised to treatment with a fixed combination of perindopril plus indapamide or matching placebo, in addition to current therapy [25]. After a mean follow-up of 4.3 years, the combination therapy reduced the progression from normoalbuminuria to microalbuminuria. In both studies, the nephroprotective effect was independent of its effect on blood pressure. Interestingly, this progression was not prevented with monotherapy. No studies have shown that the progression of microalbuminuria to normoalbuminuria in subjects with diabetes mellitus type 1 can be stopped.

When renal outcomes were evaluated in the ACCOMPLISH trial, it was found that the combination benazepril plus amlodipine was more effective than the combination of ACEI plus hydrochlorothiazide in delaying progression to nephropathy [26].

Our group found that the combination of an ACEl with a calcium antagonist was more effective than ACEI monotherapy in decreasing proteinuria and slowing down renal deterioration in normotensive type 2 diabetic patients [27], and in hypertensive patients who do not respond to monotherapy [28].

\section{Hemodynamic aspects}

Two studies evaluated the effect of combining an ARB plus calcium antagonist compared with an ARB plus hydrochlorothiazide on the central pressure in hypertensive patients $[29,30]$. In both studies, the combination of the ARB plus the calcium antagonist achieved greater reductions of central aortic pressure than the combinations with the natriuretic agent.

The Conduit Artery Functional Endpoint (CAFE) study recruited 2199 patients from five centres where the ASCOT trial was conducted, in whom central aortic pressures were measured at repeat visits for up to 4 years [31]. At the end of the study, and despite similar brachial systolic blood pressures between treatment groups, there were substantial reductions in central aortic pressures with the amlodipine regimen (95\% Cl: 3.3-5.4; $p<0.0001)$. The authors concluded that the differences in central aortic pressures may explain the different clinical outcomes between the two treatment arms in ASCOT.

\section{Elderly patients}

The only study that has evaluated the effect of two combinations of antihypertensive drugs in the elderly is the Combinations of OLMesartan (COLM) study, which included 5141 patients followed for an average of 3.3 years [32]. The study initially found no difference between the combinations of olmesartan with diuretic or amlodipine on outcomes in elderly patients. However, there were fewer adverse reactions in the group with calcium antagonist.

In a subanalysis of the COLM study in 2223 subjects older than 75 years, it was found that the combination with the calcium antagonist achieved a greater reduction of cases of cerebrovascular disease and generated fewer side effects than the combination with natriuretic in this age group [33].

A post hoc analysis of the Systolic Hypertension in Europe (Syst-Eur) study, which included 1074 subjects older than 60 years with a 6 years follow-up, found that the combination of nitrendipine plus enalapril was more effective than nitrendipine monotherapy in decreasing the incidence of heart failure, cardiovascular and cerebrovascular events, and total mortality [34].

\section{Vascular function}

Two studies have shown that the combination of perindopril plus indapamide [35] or trandolapril plus verapamil [36], further improved endothelium-dependent vasodilation and endothelial function compared with monotherapy. The combination of trandolapril plus verapamil also showed protection against structural alterations and reduced neointima formation.

The combination of benazepril plus amlodipine was more effective than high doses of both monotherapies in improving arterial compliance, reducing arterial stiffness and decreasing left ventricular mass [37].

Combined therapy of irbesartan plus diltiazem ameliorated endothelial dysfunction to a greater extent than both monotherapies in 150 hypertensive patients [38].

\section{Inflammation}

There are studies that show that the combination of an ACEI with a calcium antagonist is more effective than monotherapy in reducing various mediators of inflammation (such as interleukins, tumour necrosis factor and adhesion molecules) [39,40]. This anti-inflammatory effect has not been seen with diuretics [41]. 
In the OLAS study, the combination of olmesartan plus amlodipine significantly reduced the tumour necrosis factor-a, intercellular adhesion molecule-1, vascular cell adhesion molecule-1, and interleukins- $1 \mathrm{~b}, 6$ and 8 when compared with olmesartan plus hydrochlorothiazide, whereas c-reactive protein showed a similar reduction in both groups [23].

\section{Patients with heart disease}

The available evidence suggests that better results are obtained in patients with ischemic heart disease with combinations that include an RASI plus a calcium antagonist [37]. On the other hand, patients with heart failure benefit more from the combination of a diuretic plus an inhibitor of the renin-angiotensin axis [37].

\section{Other effects}

The combination of losartan plus a calcium antagonist produces greater reductions in uric acid levels than the combination of losartan plus hydrochlorothiazide [42]. This could provide additional benefits in hypertensive patients with obesity and/or hyperuricemia, whether asymptomatic or with gout.

\section{What do the guidelines say?}

We have previously commented that both JNC8 and ESHESC guidelines $[11,12]$ recommend the use of combinations of antihypertensive agents from the beginning for subjects with systolic pressure $20 \mathrm{mmHg}$ above the target, or diastolic pressure $10 \mathrm{mmHg}$ above the target or more, or in those subjects with high cardiovascular risk and/or multiple cardiovascular risk factors, to reach the therapeutic goals in the shortest time possible. The same recommendation is found in the 2017 ACC/AHA/AAPA/ABC/ACPM/AGS/APhA/ASH/ASPC/ NMA/PCNA Guideline for the Prevention, Detection, Evaluation, and Management of High Blood Pressure in Adults [4].

With regard to the type of drugs that may be used in combination therapy, the ESHESC recommends that in hypertensive patients with an increased risk of diabetes, the first-choice monotherapy should be a RASI, and if a second drug is required, a calcium antagonist is preferred [12].

On the other hand, the British NICE guidelines recommend, in subjects under 55 years of age, to start with a reninangiotensin axis inhibitor and, if necessary, add a calcium antagonist [43]. NICE itself establishes that, in those over 55 years of age, the initial drug should be a calcium antagonist, and if the management goals are not achieved, a RASI should be added [43].

In both cases, NICE reserves diuretic agents as a third option, and if it must be used, it suggests chlorthalidone or indapamide instead of hydrochlorothiazide [43].

The 2017 ACC/AHA/AAPA/ABC/ACPM/AGS/APhA/ASH/ ASPC/NMA/PCNA Guideline for the Prevention, Detection,
Evaluation, and Management of High Blood Pressure in Adults recommends the combination of two first-line agents of different classes [4].

\section{Which combination is best?}

Antihypertensive management should be individualised according to the characteristics of each patient, so it is difficult to generalise. However, two meta-analyses have recently found advantages for combinations that include a RASI with a calcium antagonist.

The first study included 25,451 patients from eight clinical studies [44] and found that associating a calcium antagonist (dihydropyridine or a nondihydropyridine) with a RASI, whether it is an inhibitor of angiotensin-converting enzyme or an angiotensin receptor blocker, was accompanied by a reduction in cardiovascular mortality, nonfatal myocardial infarction and nonfatal cerebral vascular disease (although not mortality from any cause) when compared with other combinations, despite achieving similar reductions in blood pressure.

The second meta-analysis included 49,418 patients from 27 studies [45] and found that, in hypertensive patients with type 2 diabetes mellitus, the combination of a RASI plus a calcium antagonist achieved greater reduction in mortality than monotherapy or other combinations, though it is related to a greater reduction in blood pressure figures with this combination.

\section{Questions to answer}

In all the studies that we have mentioned, and that show advantages of combinations with calcium antagonist over those that use diuretic, the natriuretic used has been hydrochlorothiazide. However, the available evidence tells us that both chlorthalidone and indapamide have a greater antihypertensive effect than hydrochlorothiazide, and both drugs have been shown to reduce more complications and damage to target organs than the thiazide agent [46].

Therefore, it would be interesting to find out if the results of the thiazide studies (such as ACCOMPLISH [14], OLAS [23] and STAR [20]) will be repeated in combination therapy studies that use chlorthalidone or indapamide as diuretics.

\section{Triple therapy}

Despite the use of dual therapy, a significant percentage of hypertensive patients will not achieve therapeutic goals. It is important to keep in mind that if after 6-8 weeks of treatment with two drugs the patient has not been controlled, it is necessary to evaluate adherence, white coat hypertension and pseudo-hypertension. If those items are eliminated as possible causes for treatment failure, then a third drug may be added [7]. Several studies suggest that triple therapy may include receiving a RASI plus a calcium antagonist and a 
natriuretic agent - preferably chlorthalidone or indapamide [47]. At present, we already have pharmaceutical formulations that include three agents in the same tablet, which should improve adherence to therapy [7].

Some recent studies already show that combinations of three agents are effective in lowering blood pressure in subjects who do not respond to dual therapy, in fact, the PerindoprilIndapamide plus AmlodipiNe in high rlSk hyperTensive patients (PIANIST) trial included 4731 patients at high or very high cardiovascular risk, with hypertension that was not properly controlled despite antihypertensive therapy, they received the fixed-dose combination of perindopril, indapamide and amlodipine. After 4 months of therapy, blood pressure targets were reached by $72.0 \%$ of patients $[6,48]$.

\section{Conclusions}

About $70 \%$ of hypertensive patients require the combination of at least two antihypertensive agents to reduce blood pressure levels below the recommended goals. Combination therapy should be initiated in patients with systolic pressure $20 \mathrm{mmHg}$ above the target or diastolic pressure $10 \mathrm{mmHg}$ above the recommended goal. Dual therapy should also be started in patients with high cardiovascular risk.
Combination therapy provides greater antihypertensive power than the use of high doses of monotherapy, adding several mechanisms of action that block various pathways of increased blood pressure, in addition to providing greater protection to target organs than monotherapy, and reduced potential for side effects.

The combinations recommended by the most commonly used guidelines include a RASI associated with a calcium antagonist or a natriuretic. Amongst these combinations, those that include a calcium antagonist have been shown to be more effective in reducing mortality, cardiovascular events, cerebrovascular events and kidney damage than those using hydrochlorothiazide. Combinations that include a calcium antagonist have been shown to have beneficial effects unrelated to their antihypertensive effect. These actions are metabolic, anti-inflammatory, renal protective, and improve vascular structure and function. Combinations that include a diuretic have given better results in patients with heart failure.

A significant percentage of patients will require triple therapy, which must include a RASI, a calcium antagonist and a natriuretic. This should be given to those patients who do not respond to dual therapy in 6-8 weeks, as the benefit is now beyond any doubt.

Disclosure and potential conflicts of interest: The authors declare no conflicts of interest. The International Committee of Medical Journal Editors (ICMJE) Potential Conflicts of Interests form for the authors are available for download at http://www.drugsincontext.com/wp-content/uploads/2018/05/dic.212531-COI.pdf

Copyright: Copyright $\odot 2018$ Guerrero-García C, Rubio-Guerra AF. Published by Drugs in Context under Creative Commons License Deed CC BY NC ND 4.0 which allows anyone to copy, distribute, and transmit the article provided it is properly attributed in the manner specified below. No commercial use without permission.

Correct attribution: Copyright @ 2018 Guerrero-García C, Rubio-Guerra AF. https://doi.org/10.7573/dic.212531. Published by Drugs in Context under Creative Commons License Deed CC BY NC ND 4.0.

Article URL: http://www.drugsincontext.com/combination-therapy-in-the-treatment-of-hypertension

Correspondence: Alberto Francisco Rubio-Guerra, Plan de San Luis S/N Esq Bandera, Col Ticomán, México D.F. C.P. 07330. clinhta@hotmail.com Provenance: invited; externally peer reviewed.

Submitted: 23 February 2018; Peer review comments to author: 12 March 2018; Revised manuscript received: 7 May 2018; Accepted: 8 May 2018; Publication date: 6 June 2018.

Drugs in Context is published by BioExcel Publishing Ltd. Registered office: Plaza Building, Lee High Road, London, England, SE13 5PT. BioExcel Publishing Limited is registered in England Number 10038393. VAT GB 252772009.

For all manuscript and submissions enquiries, contact the Editorial office dic.editorial@bioexcelpublishing.com

For all permissions, rights and reprints, contact David Hughes david.hughes@bioexcelpublishing.com

\section{References}

1. Oparil S, Acelajado MC, Bakris GL, Berlowitz DR, Cífková R, Dominiczak AF, Grassi G, Jordan J, Poulter NR, Rodgers A, Whelton PK. Hypertension. Nat Rev Dis Primers. 2018;4:18014. https://doi.org/10.1038/nrdp.2018.14

2. Sanchez RA, Ayala M, Baglivo H, Velazquez C, Burlando G, Kohlmann O, Jimenez J, Jaramillo PL, Brandao A, Valdes G, Alcocer L, Bendersky M, Ramirez AJ, Zanchetti A; Latin America Expert Group. Latin American guidelines on hypertension. Latin American Expert Group. J Hypertens. 2009;27:905-22. https://doi.org/10.1097/HJH.0b013e32832aa6d2

3. Oliva RV, Bakris GL. Management of hypertension in elderly population. J Gerontol Biol Sci Med Sci. 2012;67:1343-51. https://doi.org/10.1093/gerona/gls148 
4. Whelton PK, Carey RM, Aronow WS, Casey DE Jr, Collins KJ, Dennison Himmelfarb C, DePalma SM, Gidding S, Jamerson KA, Jones DW, MacLaughlin EJ, Muntner P, Ovbiagele B, Smith SC Jr, Spencer CC, Stafford RS, Taler SJ, Thomas RJ, Williams KA Sr, Williamson JD, Wright JT Jr. 2017 ACC/AHA/AAPA/ABC/ACPM/AGS/APhA/ASH/ ASPC/NMA/PCNA Guideline for the prevention, detection, evaluation, and management of high blood pressure in adults: a report of the American College of Cardiology/ American Heart Association Task Force on Clinical Practice Guidelines. J Am Coll Cardiol. 2017 Nov 7. pii: S0735-1097(17)41519-1. https://doi.org/10.1016/j.jacc.2017.11.006. [Epub ahead of print].

5. Pimenta E, Oparil S. Fixed combinations in the management of hypertension: patient perspectives and rationale for development and utility of the olmesartan-amlodipine combination. Vasc Health Risk Manag. 2008;4:653-64. https://doi.org/10.2147/VHRM.S2586

6. Volpe M, Gallo G, Tocci G. Is early and fast blood pressure control important in hypertension management? Int J Cardiol. 2018;254:328-32. https://doi.org/10.1016/j.ijcard.2017.12.026

7. Burnier M. Antihypertensive combination treatment: state of the art. Curr Hypertens Rep. 2015;17:51. https://doi.org/10.1007/s11906-015-0562-0

8. Wald DS, Law M, Morris JK, Bestwick JP, Wald NJ. Combination therapy versus monotherapy in reducing blood pressure: meta-analysis on 11,000 participants from 42 trials. Am J Med. 2009;122:290-300.

https://doi.org/10.1016/j.amjmed.2008.09.038

9. Rubio-Guerra AF, Castro-Serna D, Elizalde-Barrera Cl, Ramos-Brizuela LM. Current concepts in combination therapy for the treatment of hypertension: combined calcium channel blockers and RAAS inhibitors. Integr Blood Press Control. 2009;2:55-62. https://doi.org/10.2147/IBPC.S6232

10. Bakris GL. Combined therapy with a calcium channel blocker and an angiotensin II type 1 receptor blocker. J Clin Hypertens. 2008;10(1 Suppl 1):27-32. PubMed PMID:18174781

11. James PA, Oparil S, Carter BL, Cushman WC, Dennison-Himmelfarb C, Handler J, Lackland DT, LeFevre ML, MacKenzie TD, Ogedegbe O, Smith SC Jr, Svetkey LP, Taler SJ, Townsend RR, Wright JT Jr, Narva AS, Ortiz E. 2014 Evidence-Based guideline for the management of high blood pressure in adults: report from the Panel Members Appointed to the Eighth Joint National Committee (JNC 8). JAMA. 2014;311:507-20. https://doi.org/10.1001/jama.2013.284427

12. Task Force for the management of arterial hypertension of the European Society of Hypertension; Task Force for the management of arterial hypertension of the European Society of Cardiology. 2013 ESH/ESC Guidelines for the Management of Arterial Hypertension. Blood Press. 2013;22:193-278. https://doi.org/10.3109/08037051.2013.812549

13. Law MR, Morris JK, Wald NJ. Use of blood pressure lowering drugs in the prevention of cardiovascular disease: meta-analysis of 147 randomized trials in the context of expectations from prospective epidemiological studies. BMJ. 2009 May 19;338:b1665. https://doi.org/10.1136/bmj.b1665

14. Jamerson K, Weber MA, Bakris GL, Dahlof B, Pitt B, Shi V, Hester A, Gupte J, Gatlin M, Velazquez EJ. Benazepril plus amlodipine or hydrochlorothiazide for hypertension in high-risk patients. N Engl J Med. 2008;359:2417-28.

https://doi.org/10.1056/NEJMoa0806182

15. Mann JF, Schmieder RE, McQueen M, Dyal L, Schumacher H. Renal outcomes with telmisartan, ramipril, or both, in people at high vascular risk (the ONTARGET study): a multicentre, randomised, double-blind, controlled trial. Lancet. 2008;372(9638):547-53. https://doi.org/10.1016/S0140-6736(08)61236-2

16. Escobar C, Barrios V. An evaluation of the latest evidence relating to renin-angiotensin system inhibitors. Expert Opin Drug Metab Toxicol. 2013;9:847-58. https://doi.org/10.1517/17425255.2013.788149

17. Williams B, Cockcroft JR, Kario K, Zappe DH, Brunel PC, Wang Q, Guo W. Effects of sacubitril/valsartan versus olmesartan on central hemodynamics in the elderly with systolic hypertension: The PARAMETER Study. Hypertension. 2017;69:411-20. https://doi.org/10.1161/HYPERTENSIONAHA.116.08556

18. Koh KK, Quon MJ, Han SH, Lee Y, Kim SJ, Koh Y, Shin EK. Distinct vascular and metabolic effects of different classes of antihypertensive drugs. Int J Cardiol. 2010;140:73-81. https://doi.org/10.1016/j.ijcard.2008.11.017

19. Poulter NR, Wedel H, Dahlöf B, Sever PS, Beevers DG, Caulfield M, Kjeldsen SE, Kristinsson A, Mclnnes GT, Mehlsen J, Nieminen M, O'Brien E, Ostergren J, Pocock S; ASCOT Investigators. Role of blood pressure and other variables in the differential cardiovascular event rates noted in the Anglo-Scandinavian Cardiac Outcomes Trial-Blood Pressure Lowering Arm (ASCOT-BPLA). Lancet. 2005;366(9489):907-13. https://doi.org/10.1016/S0140-6736(05)67186-3

20. Bakris GL, Molitch M, Hewkin A, Kipnes M, Sarafidis P, Fakouhi K, Bacher P, Sowers J; STAR Investigators. Differences in glucose tolerance between fixed-dose antihypertensive drug combinations in people with metabolic syndrome. Diabetes Care. 2006;29:2592-97. https://doi.org/10.2337/dc06-1373

21. Rubio-Guerra AF, Vargas-Robles H, Vargas-Ayala G, Rodríguez-Lopez L, Castro-Serna D, Escalante-Acosta BA. Impact of trandolapril therapy and its combination with a calcium channel blocker on plasma adiponectin levels in patients with type 2 diabetes and hypertension. Ther Adv Cardiovasc Dis. 2011;5:193-7.

https://doi.org/10.1177/1753944711415307 
22. Rubio-Guerra AF, Vargas-Robles H, Lozano-Nuevo JJ, Elizalde-Barrera Cl, Huerta-Ramírez S, Escalante-Acosta BA. Beneficial effect of combination therapy with an angiotensin-converting enzyme inhibitor plus verapamil on circulating resistin levels in hypertensive patients with type-2 diabetes. Exp Clin Cardiol. 2012;17:202-4. PubMed PMID:23592936

23. Martinez-Martin FJ, Rodriguez-Rosas H, Peiro-Martinez I, Soriano-Perera P, Pedrianes-Martin P, Comi-Diaz C. Olmesartan/ amlodipine vs olmesartan/hydrochlorothiazide in hypertensive patients with metabolic syndrome: the OLAS study. J Hum Hypertens. 2011;25:346-53. https://doi.org/10.1038/jhh.2010.104

24. Ruggenenti P, Fassi A, Ilieva AP. Preventing microalbuminuria in type 2 diabetic patients. N Engl J Med. 2004;351:1941-51. https://doi.org/10.1056/NEJMoa042167

25. Patel A, Macmahon S, Chalmers J. Effects of a fixed dose combination of perindopril and indapamide on macrovascular and microvascular outcomes in patients with type 2 diabetes mellitus (The ADVANCED trial). Lancet. 2007;370:829-40. https://doi.org/10.1016/S0140-6736(07)61303-8

26. Bakris GL, Sarafidis PA, Weir MR, Dahlöf B, Pitt B, Jamerson K, Velazquez EJ, Staikos-Byrne L, Kelly RY, Shi V, Chiang YT, Weber MA; for the ACCOMPLISH Trial investigators. Renal outcomes with different fixed-dose combination therapies in patients with hypertension at high risk for cardiovascular events (ACCOMPLISH): a prespecified secondary analysis of a randomized controlled trial. Lancet. 2010;375:1173-81. https://doi.org/10.1016/S0140-6736(09)62100-0

27. Rubio AF, Arceo A, Vargas G, Rodríguez L, Lozano J, Treviño C. The effect of trandolapril and its fixed-dose combination with verapamil on proteinuria in normotensive adults with type 2 diabetes. Diabetes Care. 2004;27:1688-91. https://doi.org/10.2337/diacare.27.7.1688

28. Rubio AF, Treviño CJ, Vargas G, Narváez JL, Lozano JJ, Rodríguez L. Renoprotective effects of the combination trandolapril/ verapamil in patients with type 2 diabetes mellitus and hypertension. Clin Drug Invest. 2002;22:541-6. https://doi.org/10.2165/00044011-200222080-00006

29. Matsui Y, Eguchi K, O'Rourke MF, Ishikawa J, Miyashita H, Shimada K, Kario K. Differential effects between a calcium channel blocker and a diuretic when used in combination with angiotensin II receptor blocker on central aortic pressure in hypertensive patients. Hypertension. 2009;54:716-23. https://doi.org/10.1161/HYPERTENSIONAHA.109.131466

30. Khan BV, Merchant N, Rahman ST, Ahmad M, Parrott JM, Umar K, Johnson J, Ferdinand KC. Changes in central aortic pressure, endothelial function and biomarkers in hypertensive African-Americans with the cardiometabolic syndrome: comparison of amlodipine/olmesartan versus hydrochlorothiazide/losartan. Cardiorenal Med. 2013;3:221-31. https://doi.org/10.1159/000355136

31. Williams B, Lacy PS, Thom SM, Cruickshank K, Stanton A, Collier D, Hughes AD, Thurston H, O'Rourke M; CAFE Investigators; Anglo-Scandinavian Cardiac Outcomes Trial Investigators; CAFE Steering Committee and Writing Committee. Differential impact of blood pressure-lowering drugs on central aortic pressure and clinical outcomes: principal results of the Conduit Artery Function Evaluation (CAFE) study. Circulation. 2006 Mar 7;113(9):1213-25. https://doi.org/10.1161/CIRCULATIONAHA.105.595496

32. Ogihara T, Saruta T, Rakugi H, Saito I, Shimamoto K, Matsuoka H, for the COLM Investigators. Combinations of olmesartan and a calcium channel blocker or a diuretic in elderly hypertensive patients: a randomized, controlled trial. J Hypertens. 2014;32:2054-63. https://doi.org/10.1097/HJH.0000000000000281

33. Ogihara T, Saruta T, Rakugi H, Saito I, Shimamoto K, Matsuoka H, for the COLM Investigators. Combination therapy of hypertension in the elderly: a subgroup analysis of the combination of OLMesartan and a calcium channel blocker or diuretic in Japanese elderly hypertensive patients trial. Hypertens Res. 2015;38:89-96. https://doi.org/10.1038/hr.2014.144

34. Thijs L, Richart T, de Leeuw PW, Kuznetsova T, Grodzicki T, Kawecka-Jaszcz K, O’Brien E, Redón J, Birkenhäger WH, Fagard R, Staessen JA. Morbidity and mortality on combination versus monotherapy: a posthoc analysis of the Systolic Hypertension in Europe trial. J Hypertens. 2010;28:865-74. https://doi.org/10.1097/HJH.0b013e32833627c9

35. Ghiadoni L, Magagna A, Kardasz I, Taddei S, Salvetti A. Fixed dose combination of perindopril and indapamide improves peripheral vascular function in essential hypertensive patients. Am J Hypertens. 2009;22:506-12. https://doi.org/10.1038/ajh.2009.31

36. Versari D, Virdis A, Ghiadoni L, Daghini E, Duranti E, Masi S, Magagna A, Taddei S. Effect of verapamil, trandolapril and their combination on vascular function and structure in essential hypertensive patients. Atherosclerosis. 2009;205:214-20. https://doi.org/10.1016/j.atherosclerosis.2008.11.023

37. Neutel JM, Smith DH, Weber MA. Effect of antihypertensive monotherapy and combination therapy on arterial distensibility and left ventricular mass. Am J Hypertens. 2004;17:37-42. https://doi.org/10.1016/j.atherosclerosis.2008.11.023

38. Zhou T, Huang X, Cai X, Xie L. Combined treatment of irbesartan and diltiazem ameliorates endothelium dependent vasodilatation in hypertensives. Clin Exp Hypertens. 2017;39:612-18. https://doi.org/10.1080/10641963.2017.1306537

39. Siragy HM, Xue C, Webb RL. Beneficial effects of combined benazepril-amlodipine on cardiac nitric oxide, cGMP, and TNF-a production after cardiac ischemia. J Cardiovasc Pharmacol. 2006;47:636-42. https://doi.org/10.1097/01.fjc.0000211750.01326.b3

40. Rubio-Guerra AF, Vargas-Robles H, Vargas-Ayala G, Rodríguez-Lopez L, Escalante-Acosta BA. The effect of trandolapril and its fixed-dose combination with verapamil on circulating adhesion molecules levels in hypertensive patients with type 2 diabetes. Clin Exp Hypertens. 2008;30:682-8. https://doi.org/10.1080/10641960802251941 
41. Riva N, Lip GY. Which is the optimal antihypertensive combination in different diseases, a renin- angiotensin-aldosterone system inhibitor with a diuretic or with a calcium channel blocker? Curr Pharm Des. 2013;19:3753-65.

https://doi.org/10.2174/13816128113199990299

42. Rubio-Guerra AF, Garro-Almendaro AK, Elizalde-Barrera Cl, Suarez-Cuenca JA, Duran-Salgado MB. Effect of losartan combined with amlodipine or with a thiazide on uric acid levels in hypertensive patients. Ther Adv Cardiovasc Dis. 2017;11:57-62. https://doi.org/10.1177/1753944716678538

43. Krause T, Lovibond K, Caulfield M, McCormack T, Williams B; Guideline Development Group. Management of hypertension: summary of NICE guidance. BMJ. 2011;343:d4891. https://doi.org/10.1136/bmj.d4891

44. Chi C, Tai C, Bai B, Yu S, Karamanou M, Wang J, Protogerou A, Blacher J, Safar ME, Zhang Y, Xu Y. Angiotensin system blockade combined with calcium channel blockers is superior to other combinations in cardiovascular protection with similar blood pressure reduction: a meta-analysis in 20,451 hypertensive patients. J Clin Hypertens (Greenwich). 2016;18:801-8. https://doi.org/10.1111/jch.12771

45. Remonti LR, Dias S, Leitão CB, Kramer CK, Klassman LP, Welton NJ, Ades AE, Gross JL. Classes of antihypertensive agents and mortality in hypertensive patients with type 2 diabetes-Network meta-analysis of randomized trials. J Diabetes Complications. 2016;30:1192-200. https://doi.org/10.1016/j.jdiacomp.2016.04.020

46. Dorsch MP, Gillespie BW, Erickson SR, Bleske BE, Weder AB. Chlorthalidone reduces cardiovascular events compared with hydrochlorothiazide: a retrospective cohort analysis. Hypertension. 2011;57:689-94 https://doi.org/10.1161/HYPERTENSIONAHA.110.161505

47. Gudsoorkar PS, Tobe SW. Changing concepts in hypertension management. J Hum Hypertens. 2017;31:763-7. https://doi.org/10.1038/jhh.2017.57

48. Tóth K; PIANIST Investigators. Antihypertensive efficacy of triple combination perindopril/indapamide plus amlodipine in highrisk hypertensives: results of the PIANIST study (Perindopril-Indapamide plus AmlodipiNe in high rISk hyperTensive patients). Am J Cardiovasc Drugs. 2014;14:137-45. https://doi.org/10.1007/s40256-014-0067-2 